\title{
Pulmonary Metastases of a Uterine Smooth Muscle Tumour with Undefined Malignancy Potential
}

\author{
Lungenmetastasen eines glattmuskulären, uterinen Tumors \\ mit nicht definiertem Malignitätspotenzial
}

Authors

Affiliations
M. Esch ${ }^{1}$, M. Teschner ${ }^{1}$, J.-H. Braesen ${ }^{2}$

${ }^{1}$ Department of Thoracic Surgery, Klinikum Delmenhorst gGmbH, Delmenhorst

2 Pathologie Hamburg-West, Hamburg

\author{
Key words \\ - uterus \\ - metastasis \\ - hormone receptor \\ - uterus sarcoma \\ - benign uterus tumours \\ Schlüsselwörter \\ - Uterus \\ - Metastasierung \\ - Hormonrezeptor \\ - Uterussarkom \\ - benigne Uterustumoren
}

Deutschsprachige Zusatzinformationen online abrufbar unter: www.thieme-connect.de/ ejournals/toc/gebfra

\section{received 2.11 .2013 \\ revised 8.12.2013 \\ accepted 12.1.2014}

\section{Bibliography}

DOI http://dx.doi.org/

10.1055/s-0034-1368182

Geburtsh Frauenheilk 2014; 74 :

288-292 @ Georg Thieme

Verlag KG Stuttgart - New York . ISSN 0016-5751

\section{Correspondence}

\section{Matthias Esch, Dr. med., MA}

Klinikum Delmenhorst gGmbH

Department of Thoracic Surgery Wildeshauser Straße 92

27753 Delmenhorst

esch.matthias@

klinikum-delmenhorst.de

\section{Abstract \\ $\nabla$}

Smooth muscle neoplasms with atypical proliferative behaviour, but without clear histopathological malignancy represent a diagnostic and therapeutic challenge, as distinction from a sarcoma can be difficult and no guaranteed treatment recommendations are available due to the rarity of these changes. In the event of uncertain primary histology, even metastases cannot be assessed as malignancy criteria, but may contribute to the clarification of the histology. Similarities with other smooth muscle proliferations, such as lymphangioleiomyomatosis, are striking. The diagnostic difficulties and treatment options are explained based on the example of a 59-year-old patient, in whom a retroperitoneal mass and pulmonary lesion of such a tumour occurred 4 years after a hysterectomy. Even though the genesis and histological diagnostics have not been conclusively clarified, slow growth and a low recurrence rate for post-menopausal patients allow for a wait-and-see approach, whereby the option for anti-hormonal treatment exists in the event of positive evidence of hormone receptors.

\section{Introduction}

$\nabla$

Although uterine leiomyomas represent the most frequent gynaecological tumours, clear histopathological classification of these tumours is not possible if an atypical growth pattern, metastatic dissemination or extra-uterine relapse is present. In particular, the distinction from a leiomyosarcoma may be difficult in these cases. The classification of the dignity of extra-uterine manifestations of uterine leiomyomas has been the subject of controversial discussion since the initial descrip-

\section{Zusammenfassung \\ $\nabla$}

Glattmuskuläre Neoplasien mit zwar atypischem Wachstumsverhalten, aber ohne eindeutige histopathologische Malignitätszeichen stellen eine diagnostische und therapeutische Herausforderung dar, da die Abgrenzung zu einem Sarkom schwierig sein kann und es aufgrund der Seltenheit dieser Veränderungen keine gesicherten Therapieempfehlungen gibt. Bei unsicherer Primärhistologie können selbst Metastasen nicht als Malignitätskriterium gewertet werden, aber zur Klärung der Histologie beitragen. Auffällig sind Ähnlichkeiten zu anderen glattmuskulären Proliferationen, wie der Lymphangioleiomyomatose. Anhand des Beispiels einer 59-jährigen Patientin, bei der 4 Jahre nach Hysterektomie eine retroperitoneale Raumforderung sowie pulmonale Herde eines solchen Tumors auftraten, werden die Schwierigkeiten der Diagnostik sowie die therapeutischen Optionen erläutert. Obwohl Genese und histologische Diagnostik nicht abschließend geklärt sind, erlauben ein langsames Wachstum sowie eine niedrige Rezidivrate bei postmenopausalen Patientinnen ein abwartendes Verhalten, wobei bei positivem Nachweis von Hormonrezeptoren die Möglichkeit einer antihormonellen Therapie besteht.

tion of a "benign, metastasising fibro leiomyoma" by Steiner [1] in 1939. Metastasis or a lower mitosis index is not sufficient for assessment in these cases. According to the current WHO recommendations on histological tumour classification [2], cell atypia as well as coagulative necrosis must be considered when assessing the malignancy potential, whereby none of the criteria alone is sufficient for a diagnosis. Despite this extended panel of criteria and broader immunohistochemical marker profiles, a clear dignity classification of some of these neoplasias has not been possible to 

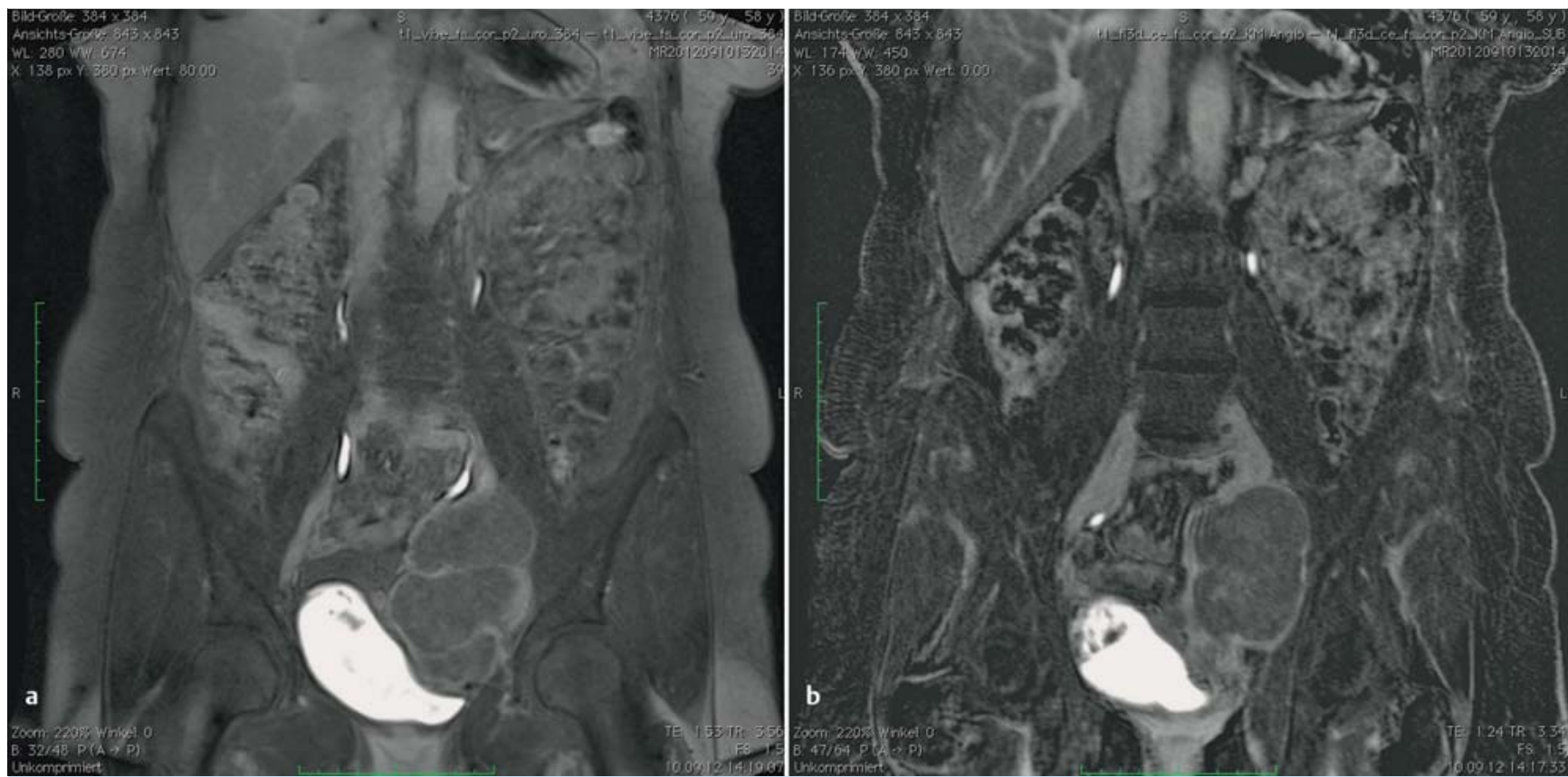

Fig. $1 \mathbf{a}$ and $\mathbf{b}$ Retroperitoneal lower abdominal tumour, encircling the left ureter (a) and translocation of the iliac vessels (b) in the MRI scan.

date, so that a heterogeneous group of "smooth muscle tumour of unknown malignant potential (STUMP) was created as a collection of these borderline cases, which also included benign, metastasising leiomyomas (BML) [3]. The most frequent location is the uterus; other smooth muscle structures, such as the diaphragm, vessel walls or ureter, are rarely described, and no oestrogen receptors can be identified in these extra-uterine cases. [4] (๑ Table 1).

\section{Case Description \\ $\nabla$}

As part of a regular medical check-up of an otherwise healthy 59 year-old, childless woman, on whom an abdominal hysterectomy with adnectomy was performed 4 years previous due to a symptomatic uterine myomatosis, a large, retroperitoneal neoplasia was discovered, which had translocated the ureter and iliac vessels and which, based on magnetic resonance imaging ( $\bullet$ Fig. 1 ), appeared to be a sarcoma. The tumour was removed transabdominally and displayed an encircling of the ureter which made a partial resection with ureterovesicostomy necessary. The iliac vessels had been translocated but not infiltrated. The histological examination confirmed the $\mathrm{R} 0$ resection of an $11.5 \mathrm{~m}$ smooth muscle tumour, which was suspiciously similar to a highly differentiated leiomyosarcoma (Actin/Desmin/Vimentin positive, Ki67 $5 \%$ ). The resected ureter section was tumour-free.

Subsequent computer tomographic staging showed multiple smooth parenchymal lesions, up to $8 \mathrm{~mm}$ in size, in all pulmonary lobes, focussed on the right, and showing irregular contrast in the X-ray ( Fig. 2). Conspicuous lymphomas or other pathological findings were not evident. A wait-and-see approach was not possible due to the unclear genesis of the pulmonary lesions and suspicion of a leiomyoscaroma; the patient was therefore admitted to surgical removal of the lesion with further histological diagnostics. The patient was in a good general condition and was employed. Regular medication in the form of an estradiol gel was prescribed for menopausal complaints.

A right thoracic exploration took place via an anterolateral minor thoracotomy with extra-anatomical resection of all ipsilateral lesions due to the small size of the pulmonary changes and the localisation in the centre of the parenchyma. Macroscopically, they resembled typical, anthracotic intrapulmonary lymph nodes, which was also confirmed histologically. Only a $5 \mathrm{~mm}$ medial lobe lesion with a glazed surface and coarse consistency

Table 1 Histological criteria for diagnosis of smooth muscle uterus tumours in accordance with [9].

\begin{tabular}{|l|l|l|}
\hline $\begin{array}{l}\text { Diagnosis } \\
\text { Leiomyosarcoma }\end{array}$ & $\begin{array}{l}\text { Necrosis } \\
\text { yes }\end{array}$ & $\begin{array}{l}\text { Atypia } \\
\text { diffuse, moderate to pronounced }\end{array}$ \\
\hline & yes & not present to mild \\
any number & diffuse, moderate to pronounced \\
\hline STUMP & no & none to low-grade \\
\hline & no & diffuse, moderate to pronounced \\
\hline Atypical leiomyoma & no & focal, moderate to pronounced \\
\hline Leiomyoma & no & moderate to pronounced \\
\hline
\end{tabular}




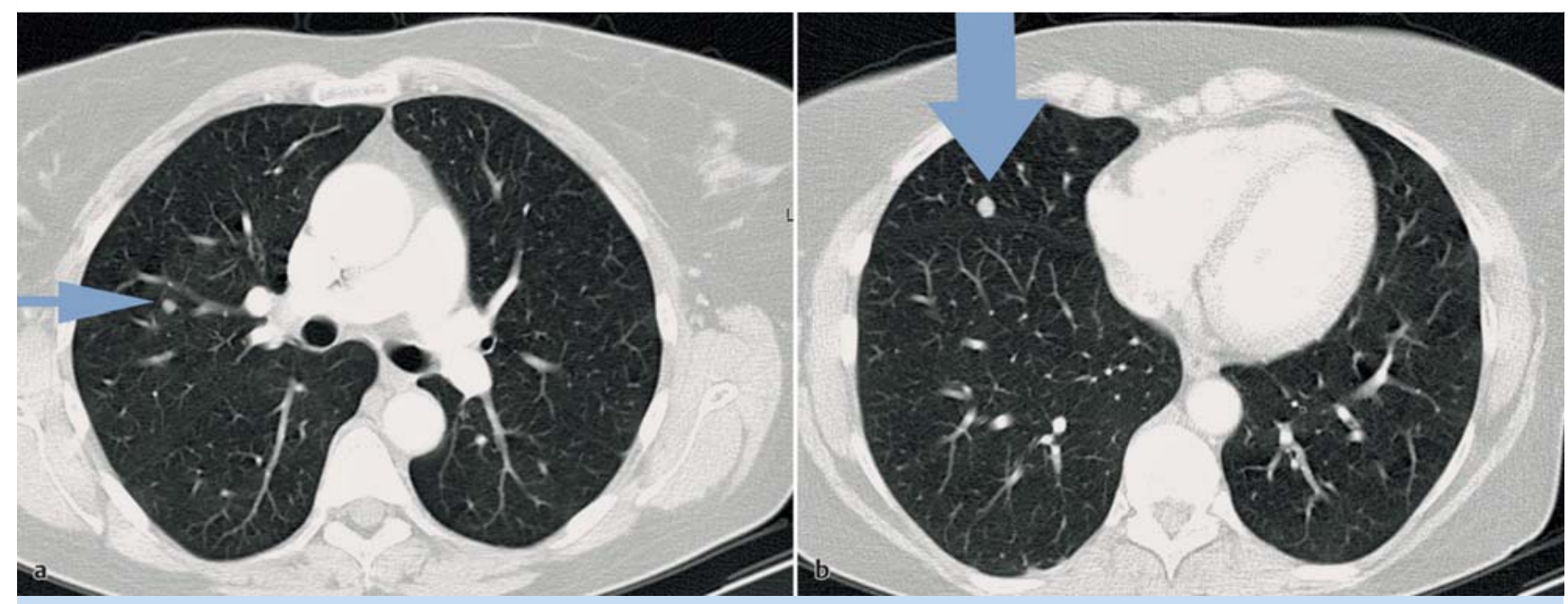

Fig. $\mathbf{2}$ a and $\mathbf{b}$ Suspected round lesions in the CT, a histological intrapulmonary lymph nodes, $\mathbf{b}$ STUMP metastasis in the medial lobe.
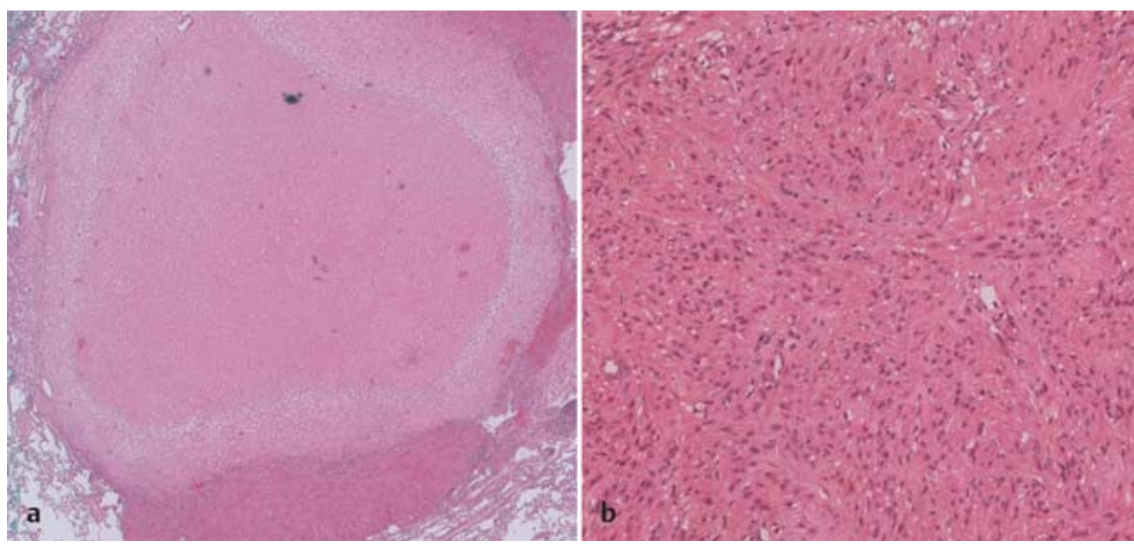

Fig. $3 \mathbf{a}$ and $\mathbf{b}$ Histology of the lung metastasis in HE staining.

a Solid, intrapulmonary lesion with defined boundaries.

b Typical smooth muscle cells in center of metastasis, arranged in fascicles.

looked suspiciously malignant. Microscopically, this was a solitary, partially necrotic, smooth muscle tumour lesion, which displayed no clear malignancy criteria ( $\bullet$ Fig. 3). Atypia or increased mitosis were not present ( $<3$ per 10 high power fields [hpf]). Immunohistochemically, the tumour cells reacted positively to actin and desmin and negatively to CD10, CD34 and S100. MIB1 stained only individual proliferating cells. Eighty-percent cell nuclei positivity was present for the oestrogen and progesterone receptors (IRS 8/12). These findings and a comparison to the sections of the previously resected retroperitoneal tumour resulted in the classification of the lung lesion as a BML metastasis.

Additional reference pathology diagnostics of the retroperitoneal tumour described a mesenchymal, spindle cell tumour, whose cells were arranged as fascicle bundles. Necrosis, nuclear atypia or mitosis were absent $(<2 / 10 \mathrm{hpf})$. A similar immunohistochemical pattern was present and the hormone receptors were also positive in this case. There was no accumulation of p53 protein. Classification was as a "smooth muscle tumour of genital type with unclear malignancy potential" due to the clear smooth muscle differentiation, the receptor positivity and the lack of clear malignancy criteria.

A comparison of the sections from the uterus myomatosis in 2008, which was also examined in consultation with a reference pathologist at the time, also took place to better assess this finding. These specimens also displayed no evidence of atypia or ne- crosis and showed only individual areas of increased mitotic activity ( $<10$ mitoses/10 hpf). The diagnosis then referred to a "mitotically active, apoplectic leiomyoma".

In summary, in consideration of all the findings, the neoplasia described is a retroperitoneal and pulmonary metastasised, well differentiated, primary uterine, smooth muscle tumour without traditional malignancy criteria.

The patient recovered quickly and was able to be released from in-patient treatment seven days after the operation. The additional abdominal sonographic and computer tomographic controls in the following 24 months to today, under medication with oestrogen receptor antagonists, showed no further changes, in particular no progression in size of the residual left pulmonary lesions.

\section{Discussion}

$\nabla$

The vast majority of smooth muscle uterine tumours can be definitively identified using a combination of histological criteria. These criteria include the presence and type of necrosis (coagulative/hyaline), the number and type of nuclear atypia, the miotic activity (mitoses per high power field, proliferation marker) and an invasive proliferative behaviour. Beside this, there is a grey area of rare, smooth muscle neoplasia that fulfil individual malig- 
nancy criteria, but which cannot be classified as a leiomyosarcoma with any certainty and are therefore combined to form the heterogeneous STUMP group. The incidence cannot currently be quantified due to the different pathological assessments and the heterogeneity of this group; however, it seems to be much lower than that of the leiomyosarcoma $[5,6]$.

Tumour growth is generally slow, so that a PET/CT diagnosis without or with only a low 18 F FDG signal can potentially differentiate these STUMP from leiomyosarcoma or metastases, which display an increased accumulation [7]. Pulmonary metastases are most common but can be observed in almost all tissues. The lesions are mostly multi-focal on both sides of the lungs, however solitary lesions may occur on rare occasions [8]. Without a histological confirmation of the extrauterine lesion there is a risk of a false positive diagnosis, as frequently - as in the above case - simultaneous, benign, reactive proliferations may be present.

STUMP diagnosis generally is achieved surgically, since biopsates are mostly insufficient for histopathological and immunohistochemical analysis and as much tissue material as possible is required. Individual interpretive difficulties also occasionally lead to different assessments of these neoplasias, which is reflected in the reassessments by the reference pathologists in retrospective studies [5,6]. A mitosis rate of $>10$ per hpf is consistently viewed as a malignancy criteria; however, the range from 5-9 per hpf cannot be reliably assessed. In addition, within tumours, areas of higher proliferation may occur next to areas without increased mitosis rates, which also limits the diagnostic reliability. The evaluation of nuclear atypia is also linked with uncertainties if the nuclei is condensed or artificially changed. For these reasons, the surgical removal of a sufficient quantity of intact tissue is recommended [9].

Coagulative necroses, especially in the area of metastases, no longer necessarily lead to the diagnosis of a leiomyosarcoma [10], as the dignity classification was originally based on studies of uterine tumours and statements on extrauterine manifestations only apply to a limited extent $[3,11]$. As a result, additional immunohistochemical criteria are included in order to improve the diagnostic reliability. These criteria include the expression of progesterone receptors, which are more distinct for leiomyomas, and an expression of $\mathrm{p} 53$, which is seen more frequently in leiomyosarcoma [12].

The formation of metastases is also still unclear. Haematogenic, peritoneal or retroperitoneal cell spreading is often assumed, as a monoclonal origin of the smooth muscle cells can be observed at the molecular and genetic levels and in almost all cases the patients had previously been pregnant or a surgical intervention had taken place in the lower abdomen [13]. This mechanism is primarily postulated for the BML and links well with the diffuse peritoneal leiomyomatosis or the intravascular myomatosis, which have already been described in combination with the BML [14]. Of interest are comparisons with pulmonary lymphangioleiomyomatosis (LAM) which displays striking similarities: a pathological proliferation of smooth muscle cells, with haematogenic or lymphogenic migration to the lungs, a lack of pathological malignancy criteria, a hormone sensitivity and a female gender specificity. This cannot be explained solely by oestrogen/ progesterone secretion, as these hormones are also produced by males; however, the uterus is unique, so that patients with pulmonary LAM not only display leiomyomas, but $90 \%$ of the patients also display uterine LAM cells [15]. Estradiol, though not progesterone, promotes the growth of LAM cells as well as BML, for which good results can be achieved with an antioestrogen treatment and with which the progression slows after menopause or after an oophorectomy and can even be reversed in some cases $[4,5,16,17]$. A special feature of the LAM cells are inactivating mutations of the tumour suppressor genes TSC1/TSC2, which lead to an activation of the mTORC1 pathway and corresponding cell growth. However, as only about $40 \%$ of patients with TSC1/TSC2 mutations develop pulmonary LAM lesions and antioestrogens have a blocking effect, mTOR activation does not seem to be sufficient and estradiol stimulation is also required [17]. TSC1/TSC2 have not previously been investigated in BML; however, the striking similarities between LAM and BML may offer an approach to better understand uterine, smooth muscle growth.

Recurrences with a latency of up to several decades occur in about $7 \%$ of STUMP cases, which tends to contradict the one-off cell spread model [18]. As a higher rate of necrosis can also be observed for extrauterine metastases, in these cases it is possible that they are closer to a leiomyosarcoma. However, most current publications are limited to the "good-natured" BML. Studies that focus on STUMP with recurrences or investigate the long-term behaviour of different metastases have not been published and could only refer to observations in individual cases or small case numbers due to the rarity of these entities [19].

Due to the low incidence of these tumours, no generally accepted treatment recommendations currently exist. A treatment indication exists for progress with parenchymal destruction or the obturation of vascular structures. An aggressive treatment with radical resection and adjuvant radiotherapy/chemotherapy, as is the case for leiomyosarcoma, is currently not indicated according to the general consensus; however, some authors recommend a radical resection with hysterectomy, bilateral oophorectomy and the removal of metastases in combination with an antihormonal treatment, especially for premenopausal patients with high endogenous oestrogen secretion $[9,20]$. In contrast, due to the hormone sensitivity and the generally benign growth behaviour following menopause, most publications recommend a watch and wait approach following histological identification or a medicinal, antioestrogen treatment regime. For BML with pulmonary metastases, for which continued tumour growth could lead to respiratory failure, zero growth or even a remission can be achieved by antihormonal treatment, even for extensive tumours. Oestrogen receptor antagonists are less effective than $\mathrm{GnRh}$ agonists or aromatase inhibitors. Progesterone also leads to a slow-down of the hypothalamic hypophyseal gonadal axis and inhibits the aromatase activity leading to regression of the pulmonary BML lesions $[4,6,18,21]$. The follow-up period should consider the often slow growth behaviour and be at least 10 years, in our opinion. Alternatively, surgical resectioning procedures are also available for preventing local organ complications [22].

The heterogeneity of the STUMP as a collective group of smooth muscle tumours that cannot be definitively classified has not permitted any reliable treatment recommendations to date. After surgical tissue removal a conservative approach or antioestrogen treatment is recommended, especially for postmenopausal patients. It is possible that the BML will be able to be distinguished from other STUMP in histopathology and clinical behaviour in the future, as they display striking similarities to other smooth muscle proliferations, such as lymphangioleiomyomatosis. TSC1/ TSC2 mutations could play a role in this regard. 


\section{Conflict of Interest}

$\nabla$

The corresponding authors or coauthors have no conflicts of interest.

\section{References}

1 Steiner PE. Metastasizing fibroleiomyoma of the uterus: report of a case and review of the literature. Am J Pathol 1939; 15: 89-110

2 Tavassoli FA, Devilee P, eds. WHO histological Classification of Tumours. Pathology and Genetics of Tumours of the Breast and female Genital Organs. 3. Auflage. Lyon: IARC Press; 2003: 233-242

3 Kempson RL, Hendrickson MR. Smooth muscle, endometrial stromal, and mixed Müllerian tumors of the uterus. Mod Pathol 2000; 13: 328-342

4 Rivera JA, Christopoulos S, Small D et al. Hormonal manipulation of benign metastasizing leiomyomas: report of two cases and review of the literature. J Clin Endocrinol Metab 2004; 89: 3183-3188

5 Ip PCC, Cheung A, Clement PB. Uterine smooth muscle tumors of uncertain malignant potential (STUMP): a clinicopathologic analysis of 16 cases. Am J Surg Pathol 2009; 33: 992-1005

$6 \mathrm{Ng}$ JSY, Han A, Chew SH et al. A clinicopathologic study of uterine smooth muscle tumours of uncertain malignant potential (STUMP). Ann Acad Med Singapore 2010; 39: 625-628

7 Di Scioscio V, Feraco P, Miglio L et al. Benign metastasizing leiomyoma of the lung: PET findings. J Thorac Imaging 2009; 24: 41-44

8 Horstmann JP, Pietra GG, Harman JA et al. Spontaneous regression of pulmonary leiomyomas during pregnancy. Cancer 1977; 39: 314-321

9 Chen S, Zhang Y, Zhang J et al. Pulmonary benign metastasizing leiomyoma from uterine leiomyoma. World J Surg Oncol 2013; 11: 163

10 Kurman RJ, Ellenson LH, Bonnett BM et al. Blaustein's Pathology of the female Genital Tract. 6th edition. New York: Springer Verlag; 2011: 453-527
11 Canciani GN, Borbos N, Duncan TJ et al. Late presentation of metastatic smooth muscle neoplasm of the uterus with low malignant potential. J Gynecol Oncol 2011; 23: 69-71

12 Hewedi IH, Radwan NA, Shash LS. Diagnostic value of progesterone receptor and p53 expression in uterine smooth muscle tumors. Diagn Pathol 2012; 7: 1

13 Nuovo G, Schmittgen T. Benign metastasizing leiomyoma of the lung: clinicopathologic, immunohistochemical and Micro-RNA analysis. Diagn Mol Pathol 2008; 17: 145-150

14 Köhler G, Evert M. Uterine Sarkome und Mischtumoren: Handbuch zur Diagnostik und Therapie. 1. Aufl. Berlin: De Gruyter; 2009: 1-180

15 Hayashi T, Kumasaka T, Mitani Ket al. Prevalence of uterine and adnexal involvement in pulmonary lymphangioleiomyomatosis: a clinicopathological study of 10 patients. Am J Surg Pathol 2011; 35: 17761785

16 Abu-Rustum NR, Curtin JP, Burt M et al. Regression of uterine low-grade smooth-muscle tumors metastatic to the lung after oophorectomy. Obstet Gynecol 1997; 89: 850-852

17 Prizant H, Sen A, Light A et al. Uterine-specific loss of TSC2 leads to myometrial tumors in both the uterus and lungs. Mol Endocrinol 2013; 27: $1403-1414$

18 Guntupalli SR, Ramirez PT, Anderson ML et al. Uterine smooth muscle tumor of uncertain malignant potential: a retrospective analysis. Gynecol Oncol 2009; 113: 324-326

19 Bastian A, Pilippou S, Bollow M et al. Das „benigne“ metastasierende Leiomyom-Fallsammlung und therapeutische Optionen. Pneumologie 2007; 61: 568-573

20 Yoon G, Kim TJ, Sung CO et al. Benign metastasizing leiomyoma with multiple lymph node metastasis: a case report. Cancer Res Treat 2001; 43: 131-133

$21 \mathrm{Ki} \mathrm{EY,} \mathrm{Hwang} \mathrm{SJ,} \mathrm{Lee} \mathrm{KH} \mathrm{et} \mathrm{al.} \mathrm{Benign} \mathrm{metastasizing} \mathrm{leiomyoma} \mathrm{of} \mathrm{the}$ lung. World J Surg Oncol 2013; 11: 279

22 Hoetzenecker K, Ankersmit HJ, Aigner C et al. Consequences of a waitand-see strategy for benign metastasizing leiomyomatosis of the lung. Ann Thorac Surg 2009; 87: 613-614 